\title{
Inclusion Complex of $\alpha$-Lipoic Acid Containing Alkalizer for Improving the Solubility and Stability Prepared by Co-grinding
}

\author{
M. ZHENG, W. TANG ${ }^{1}$, R. KONG AND X. ZHU1* \\ Collaborative Innovation Center of Yangtze River Delta Region Green Pharmaceuticals, ${ }^{1}$ College of Pharmaceutical Sciences, \\ Zhejiang University of Technology, No.18, Chaowang Road, Hangzhou 310014, China
}

Zheng, et al.: Inclusion Complex of $\alpha$-Lipoic Acid Containing Alkalizer

\begin{abstract}
The inclusion complex was prepared by co-grinding $\alpha$-lipoic acid with hydroxypropyl- $\beta$-cyclodextrin and alkalizer to enhance the solubility and stability of $\alpha$-lipoic acid. Lipoic acid was chosen as a model drug because of its poor and pH-dependent aqueous solubility. Sodium carbonate and sodium bicarbonate were chosen as the $\mathrm{pH}$ regulators. Furthermore, the study investigated the proportion of alkalizer, hydroxypropyl$\beta$-cyclodextrin and $\alpha$-lipoic acid. Although the micronization has little effect on the solubility of the drug, the formation of amorphous form has an important effect of inclusion complexes. X-ray powder diffractometry and differential scanning calorimetry were used to assess the phase change of the drugs. The in vitro dissolution test indicates that the alkalizer plays a positive factor for the drug dissolution rate enhancement. The intermolecular interactions in the inclusion complexes were investigated using Fourier transform infrared spectroscopy. It was found that the drug frequency of the $\mathrm{C}=\mathrm{O}$ band decreased or disappeared when the alkalizer was added. Thermal stability experiments showed that the inclusion complex have better stability after adding alkalizer. The solubility of $\alpha$-lipoic acid can be increased 40 times when the ratio of $\alpha$-lipoic acid and sodium carbonate is $1: 1.2$ in the ternary inclusion complex. It was evident that the inclusion compounds with alkalizer can improved the solubility and stability of $\alpha$-lipoic acid significantly.
\end{abstract}

Key words: $\alpha$-Lipoic acid, inclusion complex, alkalizer, solubility, stability

Current researches have reported that oxidative stress is a major reason for the occurrence and development of chronic diabetic complications. Reactive oxygen species (ROS) is the general term of all the reactive free radicals in the body, which have the functions of regulating vascular tone, cell adhesion and immune reaction ${ }^{[1]}$. A cluster of ROS can directly cause cell damage, which leads to the damage response of the signal transduction pathway. Furthermore ROS can produce a vicious cycle due to the tissue damage eventually ${ }^{[2]}$. Antioxidant system plays an important role in diabetes and its complications. Improving oxidative stress state may be an effective measure to prevent and cure chronic complications of diabetes. Therefore, antioxidant treatment will become an important part of the diabetes medication. $\alpha$-Lipoic acid (LA) can reduce the formation of oxidative stress and the advanced glycation end products (AGEs) ${ }^{[3]}$. LA has been an important measure for the prevention and treatment of diabetes ${ }^{[4]}$. In Germany, LA has been used

*Address for correspondence E-mail: zxy@zjut.edu.cn

544 for the treatment of diabetes induction of neuropathy more than $30 \mathrm{y}$. LA is the only antioxidant, which can be dissolved by the water-soluble and fat-soluble solutions simultaneously ${ }^{[5,6]}$. Therefore, LA is also used as food additive or antiaging agent in cosmetic applications.

LA is a fatty acid containing sulphur forming an intramolecular disulphide bond in its oxidized form (fig. 1). In the chemical structure, due to the high electron density of 1,2-dithiolane ring, there is a high tendency for reduction of other redox-sensitive molecules ${ }^{[7]}$. LA is unstable to light and heat, and polymerization occurs easily when the temperature is close to or higher than

This is an open access article distributed under the terms of the Creative Commons Attribution-NonCommercial-ShareAlike 3.0 License, which allows others to remix, tweak, and build upon the work non-commercially, as long as the author is credited and the new creations are licensed under the identical terms

Accepted 17 May 2017

Revised 14 January 2017

Received 19 October 2016

Indian J Pharm Sci 2017;79(4):544-552 


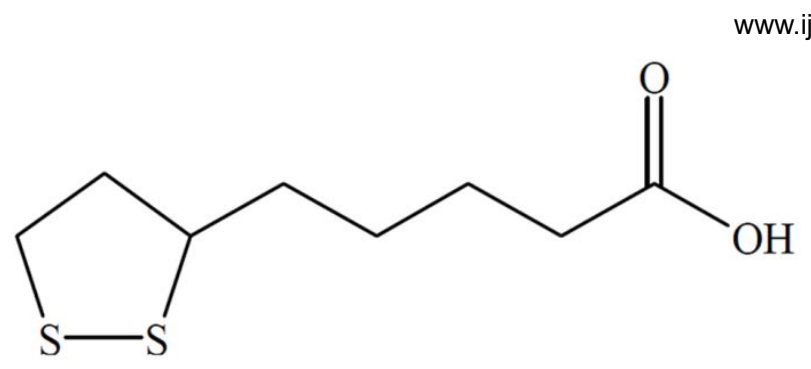

Fig. 1: Chemical structure of $\alpha$-lipoic acid

the melting point $\left(58.6^{\circ}\right)^{[8]}$. Due to its low solubility in water, there are some limitations of LA in the practical application. It is necessary to produce a product, which has higher solubility and stability ${ }^{[7-10]}$.

Hydroxypropyl- $\beta$-cyclodextrin $\quad(\mathrm{HP}-\beta-\mathrm{CD})$ is the hydrophilic derivative of $\beta$-cyclodextrin and 1,2-propylene oxide obtained by condensation reaction. It is the one of best cyclodextrin derivatives and has been widely used in pharmaceutical preparations currently for drug solubilisation and improved stability ${ }^{[11]}$. HP- $\beta-C D$ can maintain its stability in alkali, strong light and heat conditions, and its low price is suitable for industrial production.

For weakly acidic or basic drugs, the $\mathrm{pH}$ value has a great influence on its solubility in water. Because of the change of $\mathrm{pH}$ value in the solution, the hydrogen ion concentration changes obviously, which leads to the great changes of drug solubility ${ }^{[12]}$. The following Henderson-Hasselbalch equation, which reveals the relationship between the solubility of the weak acid and the $\mathrm{pH}$. Eqn. $1, \mathrm{~S}=\mathrm{S}_{0}\left[1+10^{(\mathrm{pH}-\mathrm{pKa})}\right]$, where, $\mathrm{S}_{0}$ is the natural solubility of the drug in the water, $\mathrm{S}$ is the solubility of the drug in this $\mathrm{pH}$ value, $\mathrm{pKa}$ is a polar parameter of the solute with a certain degree of dissociation in aqueous solution. With the increase of the $\mathrm{pH}$ value of the solution, the solubility of the drug can be increased.

Microenvironment $\mathrm{pH}\left(\mathrm{pH}_{\mathrm{M}}\right)$ can be defined as the $\mathrm{pH}$ of the saturated solution in the immediate vicinity of the drug particles ${ }^{[13]}$. The $\mathrm{pH}_{\mathrm{M}}$ control technology is adds a certain amount of $\mathrm{pH}_{\mathrm{M}}$ modifier (acidic agent or alkalizer) in the prescription to control the $\mathrm{pH}_{\mathrm{M}}$. Thus, the drug can be released in a predetermined pattern and independent of the environment $\mathrm{pH}$. The $\mathrm{pH}_{\mathrm{M}}$ control technology has been introduced into the process of forming the solid dispersion $(\mathrm{SD})^{[14]}$. The ternary SDs can not only achieve the drug release of non $\mathrm{pH}$ dependence, but can maintain a high degree of drug dispersion, and prevent the recrystallization of an amorphous SD system ${ }^{[15]}$. It shows a unique advantage in drug solubilisation and promotion of dissolution ${ }^{[16,17]}$.
Many kinds of LA-CD inclusion complexes have been reported in recent years ${ }^{[18,19]}$. Hideko Maeda, et al. have previously reported a study on the LA and SBE- $\beta$-CD inclusion complex by spectroscopic and thermodynamic analysis although the improvement of solubility of LA is limited ${ }^{[18]}$. However, the limitation of aqueous solubility of those inclusion compounds results that they cannot meet the need of further research. In this article, the $\mathrm{pH}$ regulator was imagined to increase the water solubility and stability of LA further by introducing it into the inclusion complex system; the types and the amount of $\mathrm{pH}$ regulators were deeply studied. Mechanochemical action was chosen as the preparation method, because it is not only environmentally friendly, but also an effective method to improve the water solubility of poorly soluble drugs ${ }^{[20-23]}$. The content of LA was determined by high performance liquid chromatography (HPLC), and Fourier transform infrared spectroscopy (FTIR) was used to instrumental characterization of the structural behaviour and molecular interaction of compounds. Differential scanning calorimetry (DSC) and powder X-ray diffraction (XRD) were used to observe the crystalline form and crystallinity of drug in compounds. In addition, the stability of those binary or ternary compounds has been deeply studied in this paper.

\section{MATERIALS AND METHODS}

LA (purity 99\%) was supplied by Xi'an Realin Biotechnology Co., Ltd (Xi'an, ShanXi), HP- $\beta-C D$ was obtained from Qianhui Fine Chemical Co., Ltd (Zibo, China), the $\mathrm{pH}$ regulators $\mathrm{Na}_{2} \mathrm{CO}_{3}$, citric acid, $\mathrm{NaHCO}_{3}$ and $\mathrm{NaOH}$ were purchased from Zhejiang Aoxing Biotechnology Co., Ltd (Taizhou, China), ethanol (purity 99.8\%) was obtained from Hangzhou Bangyi Chemical Co., Ltd (Hangzhou, China).

\section{Preparation of samples:}

LA-HP- $\beta$-CD inclusion complex was prepared by co-grinding $412 \mathrm{mg}$ LA and $3074 \mathrm{mg}$ HP- $\beta$-CD placed in a $25 \mathrm{ml}$ stainless steel milling jar containing a third tank volume of $12 \mathrm{~mm}$ diameter steel balls and milling $2 \mathrm{~h}$ at $150 \mathrm{rpm}$ using a planetary ball mill (Retsch, Verder Shanghai Instruments and Equipment Co., Ltd). The solid product were filtered by 100 mesh sieve and used for subsequent studies.

LA-HP- $\beta-C D$ inclusion complex containing $\mathrm{pH}$ regulator was prepared by co-grinding: $3074 \mathrm{mg}$ HP- $\beta$-CD and $412 \mathrm{mg}$ LA were added in a measuring 
flask with continuous stirring. Then transferred the mixture to the jar of the planetary ball mill containing a third tank volume of $12 \mathrm{~mm}$ diameter steel balls, and added in different molar ratios $\mathrm{pH}$ regulator milling $2 \mathrm{~h}$ (suspend once every $30 \mathrm{~min}$ and stirred up the mixture) at $150 \mathrm{rpm}$. The solid product was filtered by 100 mesh sieve and used for subsequent studies. The drug and polymer were simply agitated for $10 \mathrm{~min}$ in a jar to get physical mixtures (PM). All of the samples were stored in a dryer at the room temperature away from light.

\section{Solubility analysis:}

The solubility of LA was determined in the solutions in triplicate. The gastric fluid $(\mathrm{pH}=1.2)$ without pepsin was prepared by dissolving $2 \mathrm{~g} \mathrm{NaCl}$ and $7 \mathrm{ml} \mathrm{HCl}$ in $1000 \mathrm{ml}$ distilled water and $\mathrm{pH}$ was adjusted with $37 \% \mathrm{HCl}$; the enzyme-free intestinal juice $(\mathrm{pH}=6.8)$ was prepared by dissolving $6.8 \mathrm{~g} \mathrm{KH}_{2} \mathrm{PO}_{4}$ and $77 \mathrm{ml}$ $0.2 \mathrm{~mol} / 1 \mathrm{NaOH}$ in $1000 \mathrm{ml}$ distilled water and regulate with $0.2 \mathrm{~mol} / 1 \mathrm{NaOH}$ or $0.2 \mathrm{~mol} / 1 \mathrm{HCl} ; 1 \% \mathrm{w} / \mathrm{v}$ solution of the $\mathrm{pH}$ regulators $\left(\mathrm{NaOH}, \mathrm{Na}_{2} \mathrm{CO}_{3}, \mathrm{NaHCO}_{3}\right.$, citric acid) and distilled water. $5 \mathrm{ml}$ of the solution was added to brown conical flasks, respectively with excess of LA (200 mg). The flasks were put in shaking bath at $37^{\circ}$ for $24 \mathrm{~h}$ with the condition of avoiding light, and the suspension was centrifuged at $3500 \mathrm{rpm}$ for $10 \mathrm{~min}$, then the supernatant was diluted and measured accurately. The concentration of LA in the solution was measured by HPLC.

\section{Determination of $\mathrm{pH}_{\mathrm{M}}$ and solubility for complexes:}

The $\mathrm{pH}_{\mathrm{M}}$ was measured by slurry method ${ }^{[24]}$. The ternary compounds, which were prepared by ball milling $(200 \mathrm{mg}$ ), were placed into a $25 \mathrm{ml}$ conical flask containing $5 \mathrm{ml}$ purified water. The suspension was placed in $37^{\circ}$ air bath shaking table for $48 \mathrm{~h}$ with a speed of $200 \mathrm{rpm}$ to prepare the supersaturated solutions, the suspension was directly detected with a $\mathrm{pH}$ meter. Then, the solutions were centrifuged at $3500 \mathrm{rpm}$ for $10 \mathrm{~min}$, and the supernatants were filtered through a $0.45 \mu \mathrm{m}$ membrane, HPLC was used to measure the concentration of LA.

\section{FTIR, XRD and DSC:}

Infrared spectra of the samples were obtained using a Niclolet Avatar 370 instrument (Thermo Niclolet Corporation, USA) in the range of 4000-500 $\mathrm{cm}^{-1}$. All solid samples were mixed with $\mathrm{KBr}$ for compressing into a thin tablet. XRD were measured by an X'Pert PRO diffractometer (PANalytical, Holland) using $\mathrm{Cu}-\mathrm{K}$ radiation. A differential scanning calorimeter (a Mettler Q100 apparatus TA Corporation, USA) was used for thermal analysis of samples. About 3-4 mg solid sample was accurately weighed, and then placed in the pierced DSC aluminium pan. The samples were heated at a scanning speed of $10^{\circ} \mathrm{min}^{-1}$ from room temperature to $300^{\circ}$ under flowing nitrogen flux.

\section{In vitro dissolution test:}

Dissolution testing was performed using a HTY-EU802 rotating paddle apparatus (Tailin Bioengineering Equipments Co., Ltd., Hangzhou). The deionized water was chosen as the dissolution medium. The dissolution tests were carried out at $37 \pm 0.5^{\circ}$ at a rotation speed of $75 \mathrm{rpm}$ with the inclusion complexes containing $300 \mathrm{mg}$ LA. Samples were withdrawn from the dissolution medium at predetermined intervals $(5,10,15,30,45$ and $60 \mathrm{~min})$ and replaced with an equal volume of the same medium. Then the amount of LA was determined by HPLC.

\section{Stability test:}

The solid sample (containing $20 \mathrm{mg} \mathrm{LA}$ ) was added into five brown ampoule bottles respectively, then placed in a dry block bath (DHG-9240A, Yiheng scientific instrument co., LTD., Shanghai) at $70^{\circ}$ (above the melting point of LA). LA was extracted with the solution (acetonitrile: deionized water $=50: 50$ ) and detected by HPLC at 0.5, 2, 4, 8 and $24 \mathrm{~h}^{[19]}$.

\section{HPLC analysis:}

LA was measured by the Agilent HPLC system 1200 series using a reverse phase column $(150 \times 4.5 \mathrm{~mm}$, Sunfire $\mathrm{C}_{18}$ ), the column temperature was maintained at $30^{\circ}$; the flow rate was $1.0 \mathrm{ml} / \mathrm{min}$; the UV detection wavelength was $215 \mathrm{~nm}$; the injection volume was $20 \mu$ l. The liquid mobile phase was the mixed solution containing $25 \mathrm{mM}$ potassium dihydrogen phosphate solution $(\mathrm{pH}=3)$ and acetonitrile.

\section{RESULTS AND DISCUSSION}

Solubility of LA in the presence of HP- $\beta-C D$ was examined using the solubility method ${ }^{[25]}$. In the prior research, an excessive amount of LA was added to various concentrations of HP- $\beta-C D$ aqueous solution, the effect of different temperature on the solubility of LA was investigated. Fig. 2 shows the phase solubility diagram of HP- $\beta-C D$ and LA in different temperature, the solubility was improved by the addition of HP- $\beta-C D$. According to the Higuchi-Connors theory ${ }^{[26]}$, HP- $\beta-C D$ shows $A_{L}$ 
type solubility curves. Further, the inclusion ratio can be determined to 1:1. The supramolecular inclusion stability constant can be calculated through the slope and the inherent solubility of LA according to the type Eqn. 2: $\mathrm{K}=$ slope/intercept(1-slope). According to these results, as the temperature increases, the $\mathrm{K}$ value is increased indicating that the higher temperature is a favourable factor for the formation of inclusion complex.

In the pharmaceutical field, micropowder and nanometer are often used to explain the mechanism of solubilisation of drugs ${ }^{[27]}$. In the prior research, LA was used to mill alone at the speed of $100 \mathrm{rpm}$ with 10 steel $12 \mathrm{~mm}$ diameter steel balls. The powder samples were removed at $0.5,1,2,4$ and $8 \mathrm{~h}$, and detected by HPLC. The solubility of LA is 0.75 $\pm 0.02 \mathrm{mg} / \mathrm{ml}$ after co-grinding $0.5 \mathrm{~h}$ and $0.76 \pm 0.03$ $\mathrm{mg} / \mathrm{ml}$ after $8 \mathrm{~h}$. This illustrates that long time grinding has no positive effects on the solubility of LA. It can be concluded that micro powder or nanometer is not the main factor for solubilisation of LA.

The study attempted to add $\mathrm{pH}$ regulators because of the $\mathrm{pH}$-dependent peculiarity of LA. The $\mathrm{pH}$ regulator can improve its aqueous solubility significantly. An excess of LA was added in the different solutions containing different $\mathrm{pH}$ regulators (alkalizer or acidic agent) or buffer salt. Its purpose is to detect the solubility of LA in different $\mathrm{pH}$ conditions as the basis of choosing the appropriate $\mathrm{pH}$ regulator. As the results shown in Table 1, the solubility of LA was high in the solutions with a high $\mathrm{pH}$ value, and was low with the strong acidic conditions. The solubility of LA in the acidic solutions was similar to that in the distilled water,

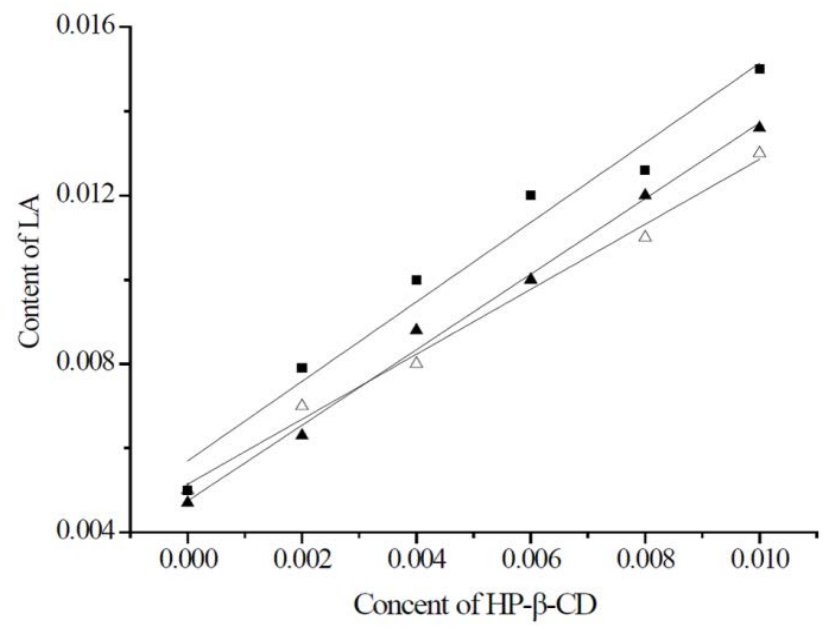

Fig. 2: Phase solubility diagram of HP- $\beta-C D$ at various temperatures $20^{\circ}(\Delta), 30^{\circ}(\Delta)$ and $37^{\circ}(\square)$

July-August 2017
TABLE 1: THE SOLUBILITY OF LA AT $37^{\circ}(n=3)$

\begin{tabular}{lc}
\hline Solution & Solubility $(\mathrm{mg} / \mathrm{ml})$ \\
\hline Distilled water & $0.86 \pm 0.04$ \\
Gastric fluid & $0.93 \pm 0.06$ \\
Intestinal fluid & $6.5 \pm 0.16$ \\
$\mathrm{NaOH}$ & $23 \pm 0.46$ \\
$\mathrm{Na}_{2} \mathrm{CO}_{3}$ & $14.9 \pm 0.21$ \\
$\mathrm{NaHCO}_{3}$ & $12.5 \pm 0.13$ \\
Citric acid & $0.84 \pm 0.05$ \\
\hline
\end{tabular}

which shows that the addition of acid has no positive effect. Therefore, the alkalizers were selected as the $\mathrm{pH}$ regulator to improve the solubility of LA in this study.

The results of in vitro dissolution test were shown in fig. $3 \mathrm{a}$ and $\mathrm{b}$. The dissolution rate of inclusion complex LA and HP- $\beta-C D$ was faster than the pure drug, and HP- $\beta$-CD had a positive effect on LA dissolution rate as shown in the curve of the PM, maybe it's related to the hydrophilicity of HP- $\beta-\mathrm{CD}$. The dissolution rate of all ternary inclusion complexes reached almost $95 \%$ in $10 \mathrm{~min}$, regardless of the type and proportion of alkalizer. It was evident that the addition of alkalizer enhanced the dissolution rate of LA obviously. However, the effect of the type and proportion of alkalizer cannot reveal in the inclusion complexes from the dissolution test. For this reason, the detailed roles of alkalizers in control the $\mathrm{pH}_{\mathrm{M}}$ of the inclusion complex and the intermolecular interactions in the system were investigated further in order to elucidate the modulating mechanism of dissolution rate.

The $\mathrm{pH}$ value of ternary inclusion complex and the content of LA were measured in order to confirm the relationship between the amount of alkalizers with the solubility of LA and the $\mathrm{pH}$ of system. Interestingly, when the amount of alkalizer was increased, the solubility of LA may not be increased. In other words, the amount of alkalizer is not an important factor to improve the solubility of LA (fig. 4 and 5). The higher $\mathrm{pH}$ value results in a higher solubility of LA although the large change of $\mathrm{pH}$ value is not significant to the solubility $(32-35 \mathrm{mg} / \mathrm{ml})$. Therefore, the solution $\mathrm{pH}$ was not the only variable to improve the solubility. The improved solubility of ternary inclusion complexes was more similar to the intermolecular interactions among the drug, $\mathrm{HP}-\beta-\mathrm{CD}$ and the $\mathrm{pH}$ regulator and the transformation of crystalline of LA. Therefore, the intermolecular interactions were analysed using FTIR spectroscopy.

FTIR was often used to detect the changes in bonding between functional groups, so as to 

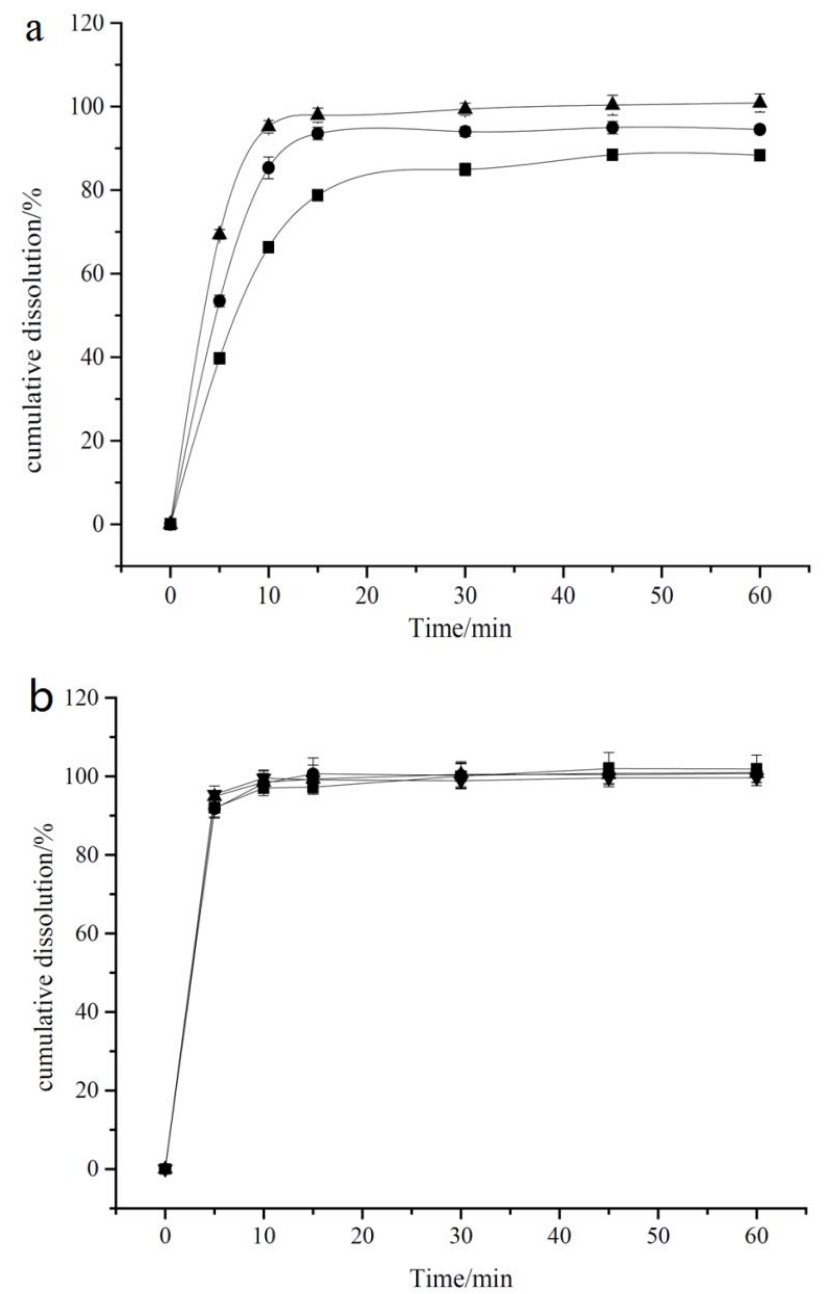

Fig. 3: Dissolution profiles of LA, PM

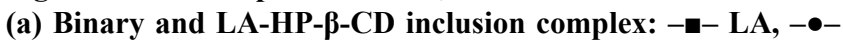
PM, - A-CG; (b) ternary LA-HP- $\beta-C D$ inclusion complex; - - $\mathrm{Na}_{2} \mathrm{CO}_{3} 0.8,-\bullet-\mathrm{Na}_{2} \mathrm{CO}_{3} 1.5,-\triangle-\mathrm{Na}_{2} \mathrm{CO}_{3} 0.8,-\nabla-\mathrm{Na}_{2} \mathrm{CO}_{3} 1.5$

speculate the interaction between molecules. As the FTIR spectra shows (fig. 6), LA does not present any bands in the broad band between 4000 and $3000 \mathrm{~cm}^{-1}$. The peak is only to be the $\mathrm{O}-\mathrm{H}$ stretching vibrations of HP- $\beta-C D$ molecule. The stretching frequency ofO-Hwas shifted from $3405 \mathrm{~cm}^{-1}$ (pure HP- $\beta-C D$ ) to $3415 \mathrm{~cm}^{-1}$ (LA-HP- $\beta-C D$ inclusion complex) due to the change of hydrogen bonds number by the intermolecular interaction during the process of formation. The expulsion of the water molecules from the HP- $\beta-C D$ cavity cannot be neglected ${ }^{[28]}$. With the complexation of LA and HP- $\beta-C D, v_{\text {as }}(C=O)$ of LA shifted from $1691 \mathrm{~cm}^{-1}$ to $1697 \mathrm{~cm}^{-1}$. The higher frequency shift can be considered as the destruction of the strong hydrogen bonding in uncomplexed LA after inclusion with HP- $\beta-C D$. These changes of vibrational band suggest that there were intermolecular interaction existed between the drug and HP- $\beta-C D$, which can be used to explain the mechanism of inclusion formation.

Compared with the LA-HP- $\beta$-CD inclusion complex, the FTIR spectra of the LA-HP- $\beta$-CD inclusion complex containing alkalizers exhibits distinct differences shown in fig. 7 and 8. Based on the variation of these FTIR bands, we could classify the alkalizers of inclusion complexes into two groups. In the first group (LA: $\mathrm{Na}_{2} \mathrm{CO}_{3}=1: 1.2,1: 1.5,1: 2$ and $\left.\mathrm{LA}: \mathrm{NaHCO}_{3}=1: 1.5,1: 2\right)$, the spectra shows that the disappearance of characteristic band of pure LA at $1691 \mathrm{~cm}^{-1}$ and the strong absorption bands at $1550-1600 \mathrm{~cm}^{-1}$ illustrating the formation of anionic carboxylate forms ${ }^{[29]}$. Meanwhile, the spectra of the second group ( $\mathrm{LA}: \mathrm{Na}_{2} \mathrm{CO}_{3}=1: 0.5,1: 0.8,1: 1$ or $\left.\mathrm{LA}: \mathrm{NaHCO}_{3}=1: 0.5,1: 0.8,1: 1,1: 1.2\right)$ shows that the characteristic band of pure LA still existed but some frequency shift appeared. This suggests that these inclusion complexes containing $\mathrm{pH}$ regulators were

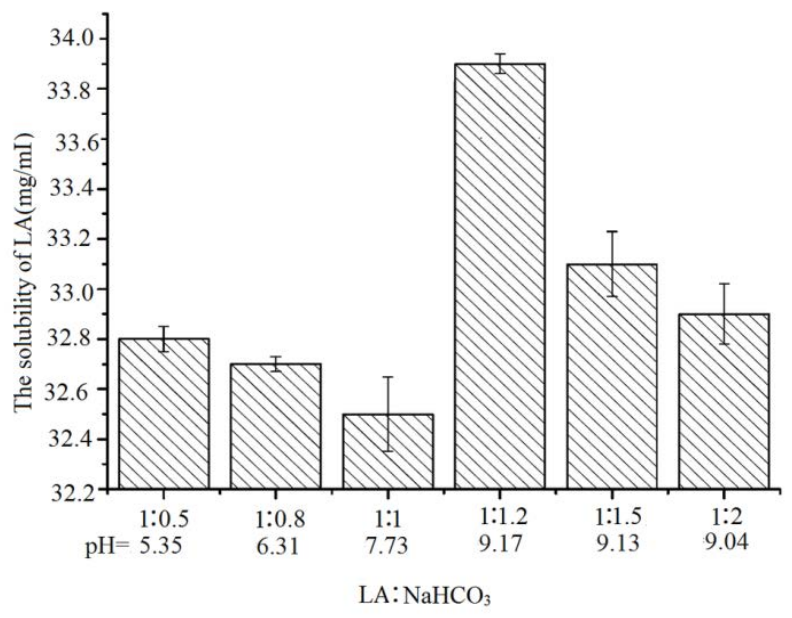

Fig. 4: Effect of different alkalizers on solubility of LA in various ratios of $\mathrm{LA}$ and $\mathrm{NaHCO}_{3}$

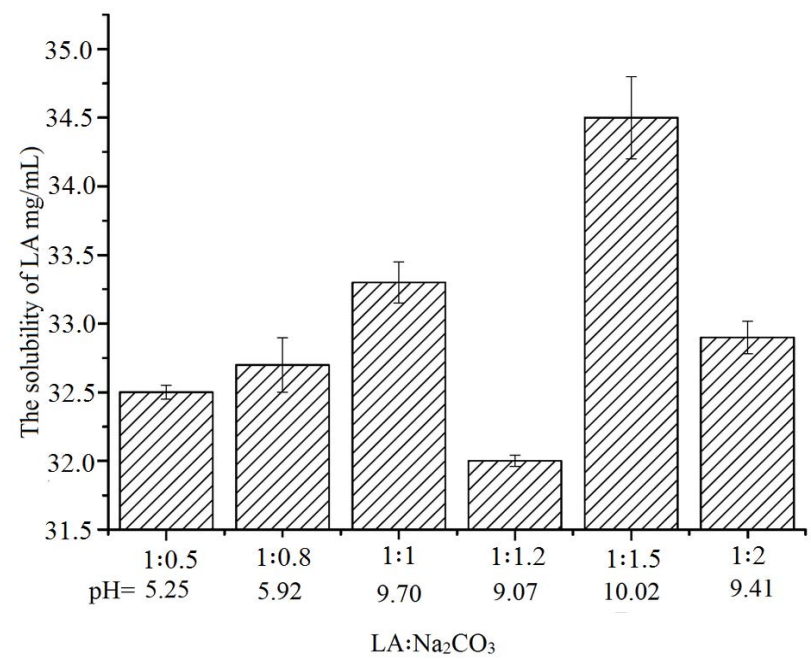

Fig. 5: Effect of different alkalizers on solubility of LA in various ratios of $\mathrm{LA}$ and $\mathrm{Na}_{2} \mathrm{CO}_{3}$ 


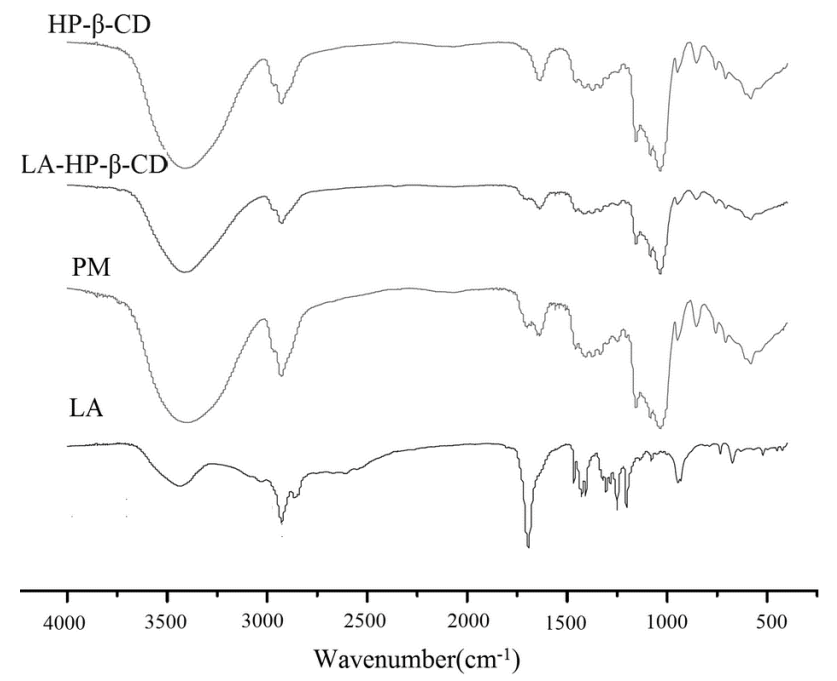

Fig. 6: FTIR spectra of LA, HP- $\beta-C D$, PM and LA-HP- $\beta-C D$ inclusion complex

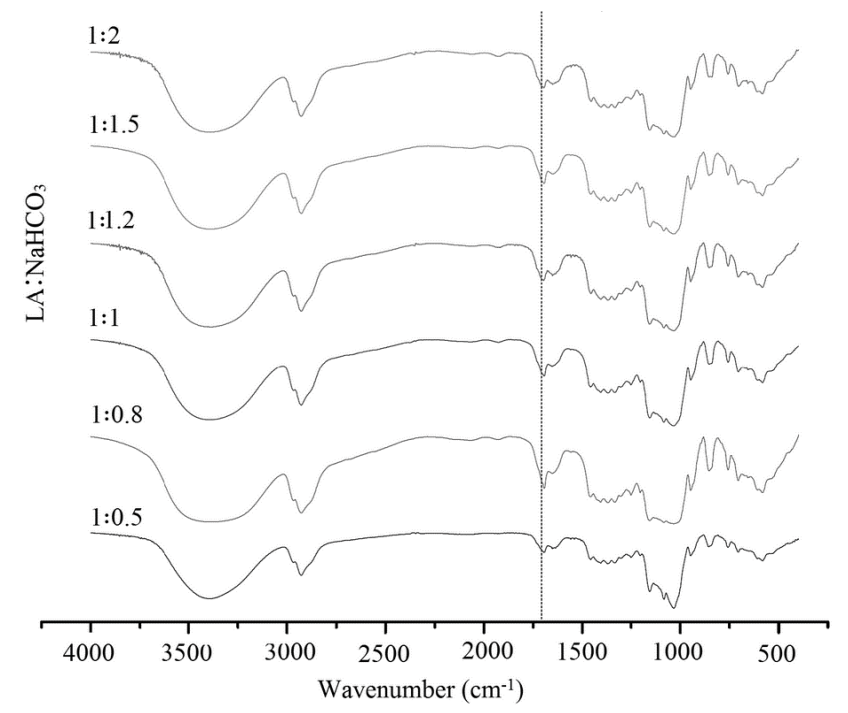

Fig. 7: FTIR spectra of LA-HP- $\beta-C D$ inclusion complex containing $\mathrm{NaHCO}_{3}$

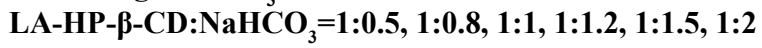

not become salt completely and some interactions exist among LA, HP- $\beta-C D$ and alkalizer.

Therefore, it is necessary to control the amount of alkalizer strictly. The large amount of alkalizer may be due to the protonation on the carboxyl groups of LA via a Lewis acid-base interaction. Meanwhile, molecular interactions and the high $\mathrm{pH}$ value inside of the system could be the main reasons of the solubility improving of LA, because of the spectra of the second groups had confirmed that these inclusion complexes had not become salt completely. Furthermore, $\mathrm{Na}_{2} \mathrm{CO}_{3}$ exhibits better ability in term of transforming LA into carboxylate form than $\mathrm{NaHCO}_{3}$. It was evident from FTIR spectra that there was a molecular interaction between the alkalizer and HP- $\beta-C D$ that results in solubility increasing in water and enhanced the dissolution of LA in the inclusion complex.

XRD patterns of LA, HP- $\beta-C D, P M$, the LA- HP- $\beta-C D$ inclusion complex and the ternary inclusion complex (LA: $\mathrm{Na}_{2} \mathrm{CO}_{3}=1: 0.8,1: 1.5$ or LA: $\mathrm{NaHCO}_{3}=1: 0.8,1: 1.5$ ) as typical samples are given in fig. 9. LA exhibited a strong characteristic peak at $23.3^{\circ}$, showing a highly crystalline in nature as indicated. No sharp diffraction peak can be found in HP- $\beta-C D$, proving that the complex substance present an amorphous state. The diffraction patterns of PM were equivalent to the superposition of LA and HP- $\beta-C D$, and the disappearance of the strong characteristic peak at $23.3^{\circ}$ of LA in LA-HP- $\beta$-CD indicated the formation of inclusion complex. The characteristic peak of the ternary inclusion complex (LA: $\mathrm{Na}_{2} \mathrm{CO}_{3}=1: 0.8$ or $\left.\mathrm{NaHCO}_{3}=1: 0.8\right)$ at $23.3^{\circ}$ was showed in the XRD pattern indicating crystal LA still existed. The new peaks of the ternary complex (LA: $\mathrm{NaHCO}_{3}=1: 0.8$ ) at $32.9^{\circ}$ and $38.1^{\circ}$ indicating a new crystal formation existed. It can be speculated that LA, HP- $\beta-C D$ and alkalizer had some reactions occurred result in the crystal structure changed. The disappearance of the distinctive peak of LA in the ternary inclusion complex (LA: $\mathrm{Na}_{2} \mathrm{CO}_{3}=1: 1.5$ or $\mathrm{NaHCO}_{3}=1: 1.5$ ) indicates the formation of carboxylate. These results are consistent with the analysis of the FTIR.

DSC thermograms of LA, HP- $\beta-C D, P M$, the LA- HP- $\beta-C D$ inclusion complex and the ternary inclusion complex (LA: $\mathrm{Na}_{2} \mathrm{CO}_{3}=1: 0.8, \quad 1: 1.5$ or $\left.\mathrm{LA}: \mathrm{NaHCO}_{3}=1: 0.8,1: 1.5\right)$ as a typical sample were showed in fig. 10. The DSC curve of pure LA exhibited

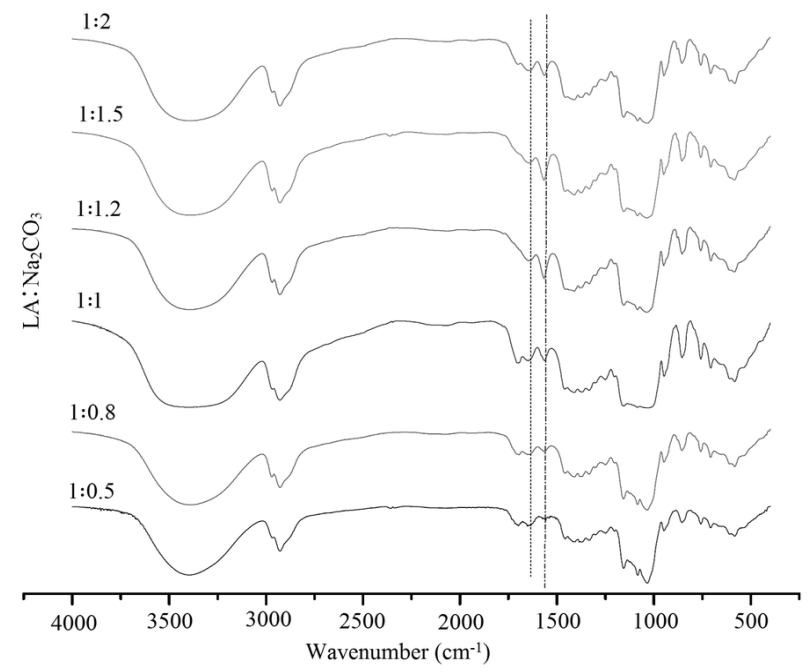

Fig. 8: FTIR spectra of LA-HP- $\beta-C D$ inclusion complex containing $\mathrm{Na}_{2} \mathrm{CO}_{3}$

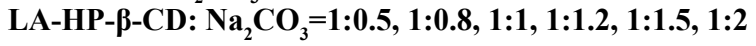



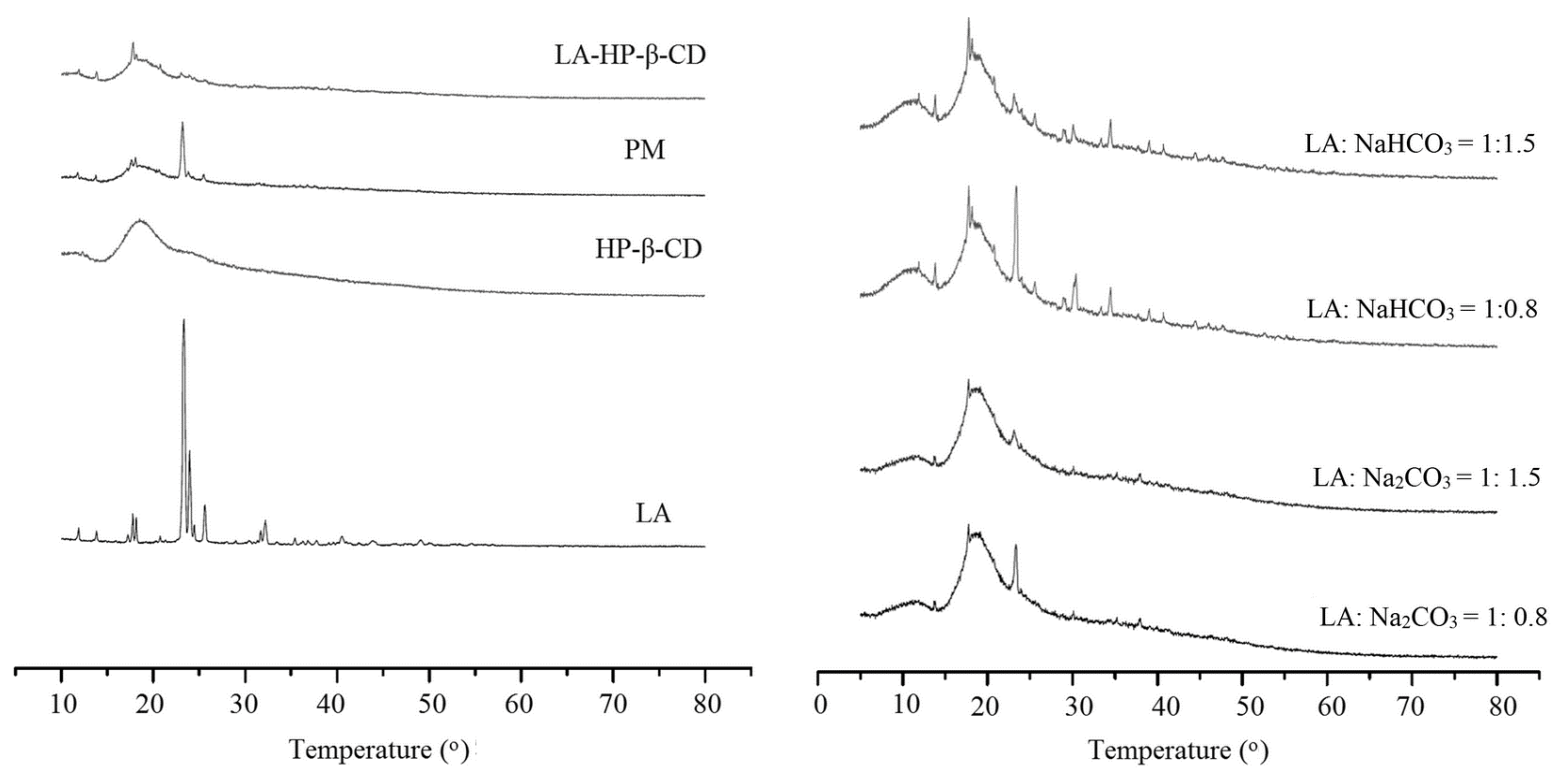

Fig. 9: XRD of LA, HP- $\beta-C D$, PM, the LA-HP- $\beta-C D$ inclusion complex and the ternary inclusion complex LA-HP- $\beta$-CD: $\mathrm{Na}_{2} \mathrm{CO}_{3}=1: 0.8,1: 1.5$ or LA-HP- $\beta-C D: \mathrm{NaHCO}_{3}=1: 0.8,1: 1.5$

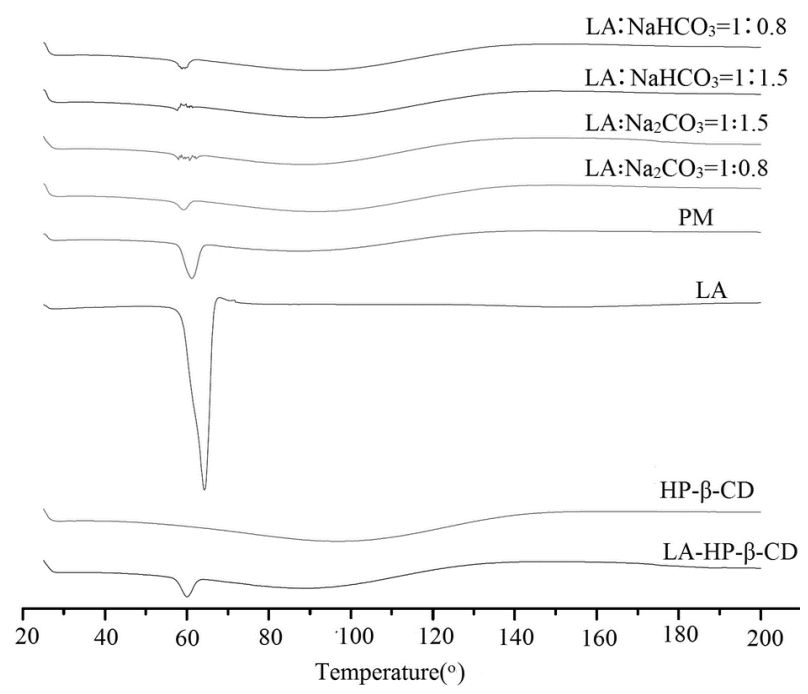

Fig. 10: DSC thermograms of LA, HP- $\beta-C D$, PM and LA-HP- $\beta$ CD inclusion complex and ternary inclusion complex $\mathrm{LA}: \mathrm{Na}_{2} \mathrm{CO}_{3}=1: 0.8,1: 1.5$ or $\mathrm{LA}: \mathrm{NaHCO}_{3}=1: 0.8,1: 1.5$

a single endothermic peak at $62.9^{\circ}$ corresponding to its own melting point. The amorphous form of HP- $\beta$-CD makes it have no endothermic peak in the DSC curve. The characteristic melting peak of LA can be found in the DSC curve of LA, revealing no interaction between LA and HP- $\beta-C D$. The weakened of the endothermic peak in the ternary inclusion complex ( $\mathrm{LA}: \mathrm{Na}_{2} \mathrm{CO}_{3}=1: 0.8$ or $\mathrm{LA}: \mathrm{NaHCO}_{3}=1: 0.8$ ) showed that the carboxylate is not formed completely, which has been verified by FTIR and XRD. The lack of an endothermic peak of the ternary inclusion complex (LA: $\mathrm{Na}_{2} \mathrm{CO}_{3}=1: 1.5$ or LA: $\mathrm{NaHCO}_{3}=1: 1.5$ ) in the DSC illustrated the drug was presence in an amorphous form.
Since that when the crystallinity is lower than $2 \%$ cannot be detected with DSC generally ${ }^{[30]}$, there is no obvious difference of the DSC curves of the inclusion complexes with or without alkalizer as the XRD patterns have. However, combined with XRD and FTIR, the conclusion can be draw that the crystallinity change of the drug and the molecules interaction are the main reasons of the solubility increased of LA, and the interaction is also different when the amount of alkalizer is different.

The thermal stability of binary or ternary LA-HP- $\beta-C D$ inclusion complex was tested by a constant temperature drying oven, and the results were showed in fig. 11 . The content of LA in the pure LA decreased rapidly under the condition of high temperature, and there is no much left after $24 \mathrm{~h}$, but the remaining amount of LA in the binary LA-HP- $\beta$-CD inclusion complex was $70 \%$ in the same condition. Compared with pure LA alone, the thermal stability has been greatly improved. The finding is consistent with prior reports on improving the thermal stability of racemic LA through complex formation with cyclodextrins ${ }^{[31]}$. It is possible that the complex formation of LA and HP- $\beta-C D$ protects the 1,2-dithiolane ring of LA, thus the LA was more stable under the high temperature. However, the ternary complexes are more stable than the binary one. The content of LA can remain above $90 \%$ after $24 \mathrm{~h}$ in ternary LA-HP- $\beta-C D$ inclusion complex. It is possible that the addition of alkalizer can enhance the interaction of molecules. The ring in the acid can obtain better protection by the interaction, so it can resist the destruction of high temperature. According 


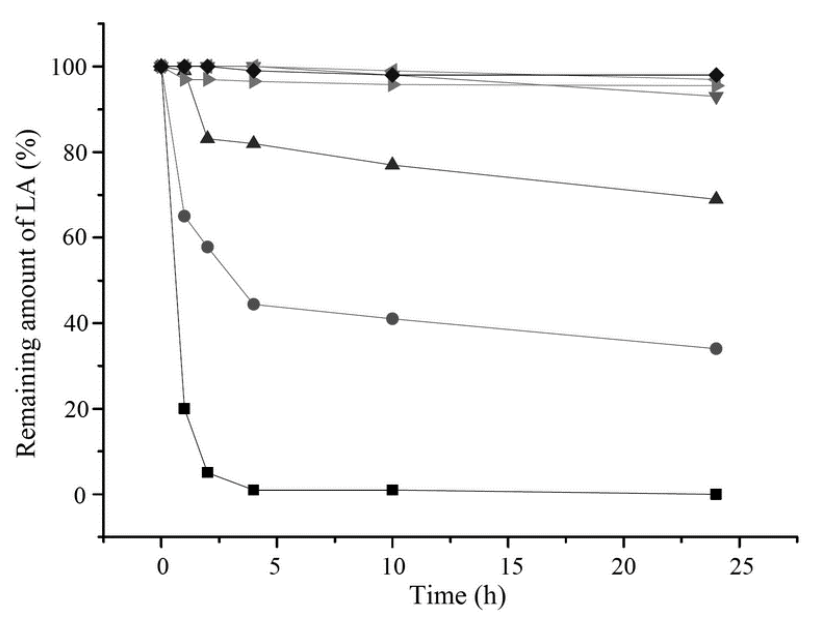

Fig. 11: Results of thermal stability study for LA, PM, binary or ternary LA-HP- $\beta$-CD inclusion complex

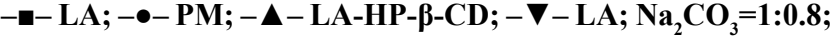
$-4-\mathrm{LA} ; \mathrm{Na}_{2} \mathrm{CO}_{3}=1: 1.5 ;--\mathrm{LA} ; \mathrm{Na}_{2} \mathrm{CO}_{3}=1: 0.8 ;-\downarrow-\mathrm{LA}$; $\mathrm{Na}_{2} \mathrm{CO}_{3}=1: 1.5$

to the results of the thermal stability study, $\mathrm{Na}_{2} \mathrm{CO}_{3}$ and $\mathrm{NaHCO}_{3}$ were chosen as the $\mathrm{pH}$ regulators to provide good stability for LA.

Inclusion complex of $\alpha$-LA containing alkalizer to improve its solubility and stability has been prepared by co-grinding. Cyclodextrin inclusion complex containing alkalizer can be a useful method to improve the solubility and stability of the $\mathrm{pH}$-dependent drugs like LA. The addition of alkalizer can increased the drug dissolution rate in water obviously. Different amount of $\mathrm{Na}_{2} \mathrm{CO}_{3}$ and $\mathrm{NaHCO}_{3}$ was selected by solubility study. The solubility of LA can be increased 40 times when the ratio of $\mathrm{LA}$ and $\mathrm{Na}_{2} \mathrm{CO}_{3}$ is 1:1.2 in the ternary inclusion complex. The stability study proved that the inclusion complex containing alkalizer exhibits better thermal stability than the LA alone. The FTIR shows that the type and the quantity of alkalizers in inclusion complex formulation are important factors because of the molecular interactions and changes of crystallinity in LA in the process of ball milling. XRD and DSC had demonstrated that the inclusion complex was exists as an amorphous form.

\section{Acknowledgements}

This work was supported by National Natural Science Foundation of China (No. 21276237).

\section{Conflict of interest}

The authors report no conflicts of interest.

\section{Financial support and sponsorship:}

Nil.

\section{REFERENCES}

1. Drog W. Free radicals in the physiological control of cell function. Physiol Rev 2002;82:47-95.

2. Laybutt DR, Kaneto H, Haaenkamp W, Grey S, Jonas JC, Sgroi $\mathrm{DC}$, et al. Increased expression of antioxidant and antiapoptotic genes in islets that may contribute to $\beta$-cell survival during chronic hyperglycemia. Diabetes 2002;51:413-23.

3. Lovell MA, Xie C, Xiong S, Markesbery WR. Protection against amyloid beta peptide and iron/hydrogen peroxide toxicity by alpha lipoic acid. J Alzheimers Dis 2003;5:229-39.

4. Packer L, Kraemer K, Rimbach G. Molecular aspects of lipoic acid in the prevention of diabetes complications. Nutrition 2001;17:888-95.

5. Bernkop-Schnurch A, Schuhbauer H, Clausen AE, Hanel R. Development of a sustained release dosage form for a-lipoic acid. I. Design and in vitro evaluation. Drug Dev Ind Pharm 2004;30:27-34.

6. Ikuta N, Tanaka A, Otsubo A, Ogawa N, Yamamoto H, Mizukami $\mathrm{T}$, et al. Spectroscopic studies of R(+)- $\alpha$-Lipoic Acid-cyclodextrin complexes. Int J Mol Sci 2014;15:20469-85.

7. Moini H, Packer L, Saris NEL. Antioxidant and prooxidant activities of $\alpha$-lipoic acid and dihydrolipoic acid. Toxicol Appl Pharmacol 2002;182:84-90.

8. Maeda H, Onodera T, Nakayama H. Inclusion complex of a-lipoic acid and modified cyclodextrins. J Incl Phenom Macrocycl Chem 2010;68:201-6.

9. Breithaupt-Grogler K, Niebch G, Schneider E, Erba K, Hermannb R, Blume HH, et al. Dose-proportionality of oral thioctic acid-coincidence of assessments via pooled plasma and individual data. Eur J Pharm Sci 1999;8:57-65.

10. Park CH, Youn HR, Lee J, Lee KU, Park JY, Koh EH, et al. Improved efficacy of appetite suppression by lipoic acid particles prepared by nanocomminution. Drug Dev Ind Pharm 2009;35:1305-11.

11. Jianmin W, Jinguo T, Xuefeng Z, Qiang X. Physicochemical characterization, identification and improved photo-stability of alpha-lipoic acid-loaded nanostructured lipid carrier. Drug Dev Ind Pharm 2014;40:201-10.

12. Irie $T$, Uekama K. Pharmaceutical applications of cyclodextrins. III. Toxicological issues and safety evaluation. J Pharm Sci 1997;86:147.

13. Badawy SI, Hussain MA. Microenvironmental $\mathrm{pH}$ modulation in solid dosage forms. J Pharm Sci 2007;96:948-59.

14. Tran PH, Tran TT, Lee BJ. Modulation of micro environmental $\mathrm{pH}$ and crystallinity of ionizable telmisartan using alkalizers in solid dispersions for controlled release. J Control Release 2008;129:59-65.

15. Siepe S, Lueckel B, Kramer A, Ries A, Gurny R. Strategies for the design of hydrophilic matrix tablets with controlled microenvironmental pH. Int J Pharm 2006;316:14-20.

16. Tran TT, Tran PH, Lee BJ. Dissolution-modulating mechanism of alkalizers and polymers in a nanoemulsifying solid dispersion containing ionizable and poorly water-soluble drug. Eur J Pharm Biopharm 2009;72:83-90.

17. Tran TD, Tran HL,Choi HG, Han HK, Lee BJ. The roles of acidifiers in solid dispersions and physical mixtures. Int $\mathrm{J}$ Pharm 2009;384:60-6.

18. Hideki T, Yuir B, Katsuhiko M. The aqueous solubility and thermal stability of $\alpha$-lipoic acid are enhanced by cyclodextrin. Biosci Biotechnol Biochem 2011;75:633-7. 


\section{www.ijpsonline.com}

19. Racz CP, Santa S, Tomoaia-Cotisel M, Borodi G, Kacso I, Pirnau A, et al. Inclusion of a-lipoic acid in $\beta$-cyclodextrin. Physical-chemical and structural characterization. J Incl Phenom Macrocycl Chem 2013;76:193-9.

20. Dushkin AV. Mechanochemical synthesis of organic compounds and rapidly-soluble materials. High-energy ball milling: mechanochemical processing of nanopowders. In: Sopicka-Lizer M, editor. High-Energy Ball Milling: Mechanochemical Processing of Nanopowders. Cambridge: Woodhead Publishing Limited; 2010. p. 224-47.

21. Xie J, Yang F, Shi X, Zhu X, Su W, Wang P. Improvement in solubility and bioavailability of puerarin by mechanochemical preparation. Drug Dev Ind Pharm 2013;39:826-35.

22. Corti G, Capasso G, Maestrelli F, Cirri M, Mura P. Phyicalchemical characterization of binary systems of metformin hydrochloride with triacetyl-b-cyclodextrin. J Pharm Biomed Anal 2007;45:480-6.

23. Zhong $\mathrm{L}, \mathrm{Zhu} \mathrm{XY}, \mathrm{Yu} \mathrm{JB}, \mathrm{Su} \mathrm{WK}$. Influence of alkalizers on dissolution properties of telmisartan in solid dispersions prepared by cogrinding. Drug Dev Ind Pharm 2014;40:1660-9.

24. Serajuddin AT, Jarowski CI. Effect of diffusion layer $\mathrm{pH}$ and solubility on the dissolution rate of pharmaceutical acids and their sodium salts. II: Salicylic acid, theophylline, and benzoic acid. J Pharm Sci 1985;74:148-54.

25. Brewster M, Loftsson T. Cyclodextrins as pharmaceutical solubilizers. Adv Drug Deliv Rev 2007;59:645-66.

26. Higuchi T, Connors KA. Phase-solubility techniques. Adv Anal Chem Instrum 1965;4:117-212.

27. Kesisoglou F, Panmai S, Wu Y. Nanosizing-Oral formulation development and biopharmaceutical evaluation. Adv Drug Del Rev 2007;59:631-44.

28. Liu L, Guo QX. The driving forces in the inclusion complexation of cyclodextrins. J Incl Phenom Macrocycl Chem 2002;42:1-14.

29. Hernandez EA, Posada B, Irizarry R, Castro ME. Role of hydrogen bonding interactions in directing one-dimensional thiol-assisted growth of silver-based nanofibers. J Phys Chem B 2005; 109:7251-7.

30. Leuner C, Dressman J. Improving drug solubility for oral delivery using solid dispersions. Eur J Pharm Biopharm 2000;50:47-60.

31. Takahashi H, Bungo Y, Mikuni K. The aqueous solubility and thermal stability of $\alpha$-lipoic acid are enhanced by cyclodextrin. Biosci Biotechnol Biochem 2011;75: 633-37. 